\title{
Água tratada magneticamente para irrigação: efeitos na produção e eficiência do uso da água na cultura da cenoura (Daucus carota L.)
}

\author{
Magnetically treated water for irrigation: effects on \\ production and efficiency of water use in carrot \\ (Daucus carota L.) crop
}
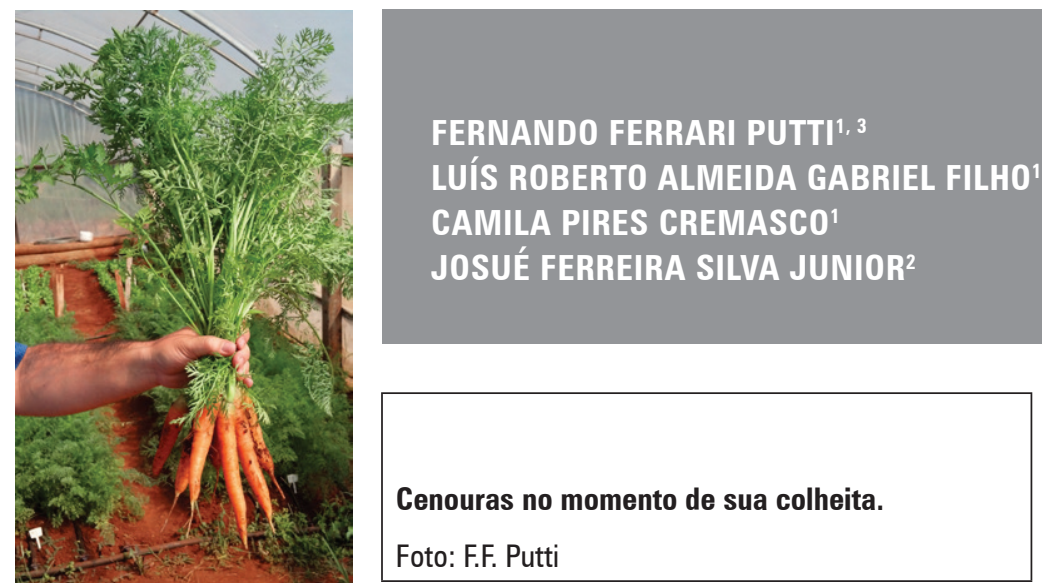

\section{RESUMO}

A cultura da cenoura vem aumentando sua representatividade na produção de hortaliças devido a seus benefícios para a saúde humana. Objetivou-se neste trabalho analisar a consequência de diferentes lâminas de irrigação utilizando água tratada magneticamente e potável para a cultura da cenoura. O experimento foi conduzido na Faculdade de Ciências Agronômicas (FCA-UNESP), Campus de Botucatu-SP (Brasil), entre os meses de setembro a dezembro de 2015. Adotou-se o delineamento experimental em blocos casualizados, em esquema fatorial de $2 \times 5 \mathrm{com} 10$ repetições. Assim, os tratamentos foram 2 tipos de água (água tratada magneticamente e potável), e 5 lâminas de reposição que corresponderam aos percentuais da evapotranspiração $(25,50,75,100$ e $125 \%$ da Etc), utilizando a irrigação por gotejamento. Constatou-se que a irrigação com água tratada magneticamente proporcionou um incremento na massa de matéria fresca, sendo que a lâmina que obteve a maior produção foi a de 100 e $125 \%$ da Etc, assim verificando a possibilidade do aumento da produtividade da cenoura. Se constatou aumento significativo para a o número de folhas, comprimento de bulbo e diâmetro para a cultura da cenoura quando irrigada com água tratada magneticamente.

$\begin{array}{r}\begin{array}{r}\text { Palavras-chave adicionais: irrigação por gotejamento, magnetismo, tubérculos, } \\ \text { gestão da água, produtividade, qualidade da colheita. }\end{array} \\ \hline\end{array}$

1 Faculdade de Ciências e Engenharia, Universidade Estadual Paulista (UNESP), Tupã-SP (Brasil). ORCID Putti, F.F.: 0000-0002-0555-9271; ORCID Filho, L.R.A.G.: 0000-0002-7269-2806; ORCID Cremasco, C.P.: 0000-0003-2465-1361

2 Faculdade de Ciências Agronômicas, Universidade Estadual Paulista (UNESP), Botucatu-SP (Brasil). ORCID Silva Junior, J.F.: 0000-0002-8057-1465

3 Autor para correspondencia.fernandoputti@tupa.unesp.br 


\section{ABSTRACT}

Carrot cultivation has increased within vegetable production because of its benefits to human health. The aim of this study was to investigate the effect of different irrigation using magnetically treated water and potable water on a carrot crop. The experiment was conducted in the Department of Rural Engineering of the Faculty of Agricultural Sciences (FCA-UNESP), Botucatu-SP Campus (Brazil), from September to December, 2015. A randomized complete block with a $2 \times 5$ factorial and 10 repetitions was adopted. Thus, the treatments included 2 types of water (potable and magnetically treated) and 5 spare blades that corresponded to the percentage of evapotranspiration $(25,50,75$, 100 and $125 \%$ ETc), with drip irrigation. The magnetically treated water irrigation yielded an increase in green root biomass, and the highest production was seen with 100 and $125 \%$ ETc, verifying the possibility of increased carrot productivity. There was a significant increase in the number of leaves, bulb length and diameter when the carrot crop was irrigated with magnetically treated water.

Additional key words: drip irrigation, magnetism, root vegetables, water management, productivity, harvest quality.

Data de recepção: 30-11-2017 Aprovado para publicação: 30-05-2018

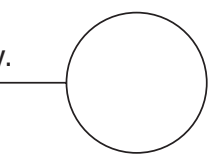

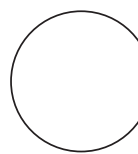

A cultura da cenoura vem se destacando em sua produção devido, principalmente, aos benefícios para a saúde humana. Atualmente está entre as dez hortaliças mais consumidas no Brasil, apresentando grande importância na questão do desenvolvimento socioeconômico do país (Silva et al., 2011, Lima Junior et al., 2014).

O cultivo de cenoura demanda um manejo de irrigação eficaz, pois devido a cultura ser sensível as condições de déficit ou excesso de água, levando a uma redução significativa na produção e produto de qualidade inferior. Caso o manejo não seja realizado de forma correta, pode ocorrer degradação da qualidade da água devido a contaminação dos recursos por defensivos agrícolas e fertilizantes. Assim, deve ser realizado de forma adequada o manejo das lavouras, objetivando maior eficiência no uso da água e nos sistemas de irrigação.

Estudos vem sendo desenvolvidos nos últimos anos com a irrigação utilizando água tratada magneticamente (ATM) na irrigação de culturas. Porém, existem poucos estudos que explicam as modificações químicas e físicas da água quando submetida ao campo magnético e o impacto dessas modificações nas culturas. Ressalta-se que de forma geral as pesquisas vêm demonstrando que a irrigação com ATM provoca o aumento na produção e qualidade das culturas (Putti et al., 2015).
As culturas do grão de bico e ervilha apresentaram aumento de produção e no maior desenvolvimento ao serem irrigadas com ATM comparadas com o controle (Grewal e Maheshwari, 2011). Maheshwari e Grewal (2009) submeteram a cultura do tomate em diferentes doses de salinidade e irrigando com ATM e água potável (AP) e, foi possível verificar o aumento nos componentes de produção, assim como a qualidade do tomate, também puderam aferir que o tratamento controle (sem salinidade e irrigado com AP) produziu menos que os tratamentos com salinidade e irrigados com ATM.

De acordo com Mohamed (2013) o tomateiro quando cultivado sobre diferentes níveis de condutividade elétrica e irrigado com ATM e AP, e constatou o incremento superior quando submetidas a irrigação com água tratada magneticamente, em todas as doses de salinidade.

Assim, pode-se observar a necessidade de estudos que comprovem o efeito da irrigação com ATM, a fim de desmistificar o efeito positivo que pode provocar nas culturas. Até o momento não foram realizados estudos que comprovem o efeito na cultura da cenoura e também o estabelecimento da lâmina ideal para o melhor manejo da cultura. Deste modo a necessidade de pesquisas que estabeleçam condições ideias de manejo para a cultura da cenoura e também otimizem as formas de reduzir o volume de água aplicado via 
irrigação, devido à crise hídrica vivenciada nos últimos anos. Desta forma o objetivo deste trabalho foi verificar o efeito de diferentes lâminas de irrigação utilizando água tratada magneticamente e potável para a cultura da cenoura.

\section{MATERIAIS E MÉTODOS}

Conduziu-se o experimento com cenoura var. Nativa em uma casa de vegetação durante os meses de setembro a dezembro de 2015. O local do experimento foi no Departamento de Engenharia Rural da UNESP, Faculdade Ciências Agronômicas, Fazenda Experimental Lageado, localizada no município de Botucatu-SP, Brasil. A região do estudo detém o clima do tipo Cfa (Clima Subtropical Úmido), segundo a classificação de Koppen (Koppen e Geiger, 1928).

O solo era do tipo Nitossolo Vermelho Distrófico Latossólico de acordo com a classificação de Carvalho et al. (2000). Apresentava estrutura moderada média/ argilosa, com as seguintes características químicas: $\mathrm{pH}\left(\mathrm{CaCl}_{2}\right)=5,9 ; \mathrm{MO}=24 \mathrm{~g} \mathrm{dm}^{-3} ; \mathrm{P}$ (resina) $=191$ $\mathrm{mg} \mathrm{dm}{ }^{-3} ; \mathrm{K}=4,8 \mathrm{mmol}_{\mathrm{c}} \mathrm{dm}^{-3} ; \mathrm{Ca}=68 \mathrm{mmol}_{\mathrm{c}} \mathrm{dm}^{-3}$; $\mathrm{Mg}=25 \mathrm{mmol}_{\mathrm{c}} \mathrm{dm}^{-3} ; \mathrm{H}+\mathrm{Al}=17 \mathrm{mmol}_{\mathrm{c}} \mathrm{dm}^{-3} ; \mathrm{SB}=67$ $\mathrm{mmol}_{\mathrm{c}} \mathrm{dm}^{-3} ; \mathrm{B}=0,51 \mathrm{mmol}_{\mathrm{c}} \mathrm{dm}^{-3} ; \mathrm{Cu}=4,8 \mathrm{mmol}_{\mathrm{c}} \mathrm{dm}$ 3; $\mathrm{Fe}=20 \mathrm{mmol}_{\mathrm{c}} \mathrm{dm}^{-3} ; \mathrm{Mn}=10,10 \mathrm{mmol}_{\mathrm{c}} \mathrm{dm}^{-3} ; \mathrm{Zn}=8$ $\mathrm{mmol}_{\mathrm{c}} \mathrm{dm}^{-3} ; \mathrm{CTC}=114 \mathrm{mmol}_{\mathrm{c}} \mathrm{dm}^{-3} ; \mathrm{V}=85 \%$.

O solo foi preparado um mês antes do plantio, utilizando-se um trator do tipo "Tobata", em que revolveu os $30 \mathrm{~cm}$ da camada superficial, após foi corrigido o solo e realizadas as adubações necessárias, levantando-se os canteiros com enxada. O controle de plantas daninhas foi realizado manualmente quando necessário.

Semeou-se diretamente no solo, em que foi realizado um sulco de aproximadamente $1 \mathrm{~cm}$ de profundidade e utilizou-se o espaçamento de $0,05 \times 0,05 \mathrm{~m}$. As parcelas mediam $1,2 \mathrm{~m}$ de largura por $3 \mathrm{~m}$ de comprimento, totalizando $3,6 \mathrm{~m}^{2}$. Realizou-se o plantio de 4 linhas, sendo desconsidera as linhas laterais e avaliou apenas as plantas centrais. As adubações foi realizada de acordo com as recomendações da cultura para a região.

O delineamento experimental adotado foi em blocos ao acaso, com dez tratamentos e dez repetições. Os tratamentos foram constituídos das lâminas de irrigação correspondente a $25,50,75,100$ e $125 \%$ da evaporação de água do tanque Classe "A" e dos tipos de água sendo potável e tratada magneticamente. Os dados climáticos do experimento foram coletados ao longo do experimento, no horário das 8 h da manhã, em que se havia instalado dentro da casa de vegetação um tanque Classe "A" e uma estação meteorológica.

Utilizou-se o equipamento da Sylocymol (Timol Group, Uberlândia-MG, Brasil), que detinha capacidade de magnetizar $5 \mathrm{~m}^{3} \mathrm{~h}^{-1}$ por hora. $O$ sistema de irrigação foi instalado de forma independente. As fitas gotejadora possuíam espaçamento de $0,30 \mathrm{~m}$ entre gotejadores, sendo sua vazão média de $1,472 \mathrm{~L} \mathrm{~h}^{-1}$, quando submetida a uma pressão de 10 m.c.a.

$\mathrm{Na}$ determinação do tempo de irrigação utilizou o método proposto por Marouelli et al. (2002) utilizando o Tanque Classe A. E para o cálculo do Kp aplicou-se os métodos proposto por Snyder (1992) e o Kc utilizado foi o recomenda 0,$80 ; 1,00 ; 95,00$, sendo no início, metade e final do ciclo, respectivamente, de acordo com a Allen et al. (1998).

Para a determinação dos efeitos das diferentes lâminas de irrigação e dos tipos de água, foram coletadas no momento da colheita 10 plantas por parcela e avaliou-se o comprimento de bulbo (CB), diâmetro de bulbo (DB), massa fresca do bulbo (MFB), massa seca do bulbo (MSB), números de folhas (NF), massa fresca das folhas (MFF), massa seca das folhas (MSF) e a eficiência do uso da água (produção/lâmina aplicada).

$\mathrm{Na}$ análise estatística aplicou a análise de variância (teste F), a 1 e $5 \%$ de probabilidade (Banzatto e Kronka, 2006), com uso do software SigmaStat e Minitab.

\section{RESULTADOS E DISCUSSÕES}

Os dados climáticos foram determinados através de uma estação meteorológica. Na tabela 1 pode-se observar os valores da temperatura e umidade média máxima e mínima durante o período de condução do experimento.

A temperatura média observada ao longo do experimento foi de $23,65^{\circ} \mathrm{C}$. Sabe-se que temperatura acima de $21^{\circ} \mathrm{C}$ favorecem o crescimento curto de raízes e de coloração diferente (Lima Junior et al., 2012). Também foi constatado que ao longo do experimento foi evaporado um total de $188,76 \mathrm{~mm}$. Na avaliação do sistema de irrigação foi constatado o coeficiente de uniformidade de distribuição (CUD) de 95\%. 
Tabela 1. Dados climáticos de temperatura, umidade máxima, média e mínima e evaporação coletados durante a execução do experimento conduzido no Departamento de Engenharia Rural, FCA-UNESP.

\begin{tabular}{|l|c|r|}
\hline \multicolumn{1}{|c|}{ Parâmetros } & \multicolumn{2}{|c|}{ Ciclo do experimento } \\
\hline \multirow{3}{*}{ Temperatura $\left({ }^{\circ} \mathrm{C}\right)$} & Mínima & $15,81 \pm 2,81$ \\
\cline { 2 - 3 } & Máxima & $32,30 \pm 5,01$ \\
\cline { 2 - 3 } & Média & $23,65 \pm 3,25$ \\
\hline \multirow{3}{*}{ Umidade relativa (\%) } & Mínima & $25,00 \pm 14,8$ \\
\cline { 2 - 3 } & Máxima & $78,00 \pm 11,0$ \\
\cline { 2 - 3 } & Média & $52,50 \pm 11,9$ \\
\hline Evaporação $(\mathrm{mm})$ & \multicolumn{2}{|c|}{188,76} \\
\hline
\end{tabular}

\pm indica desvio padrão.

Para a variável comprimento do bulbo não houve efeito significativo quando aplicado a diferentes lâminas de irrigação com ATM. E quando irrigado com água potável, ocorreu um incremento em função das lâminas de irrigação (Fig. 1).

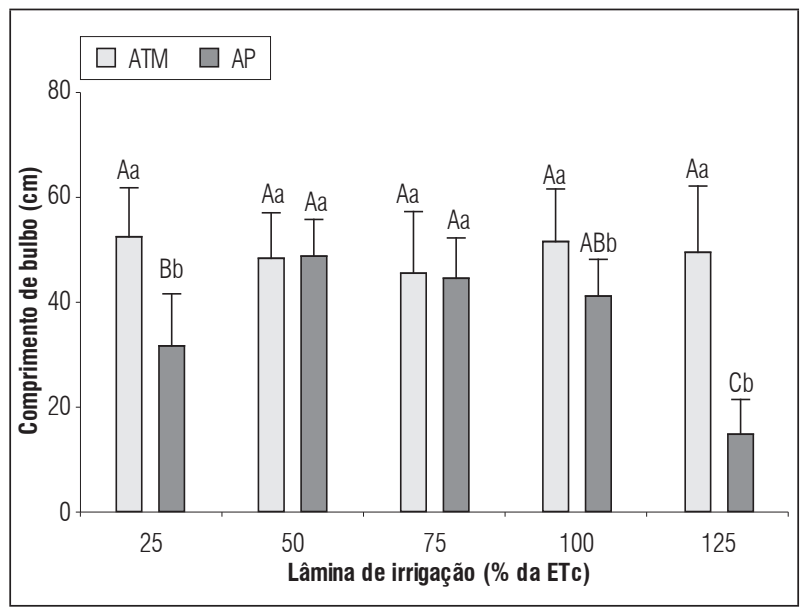

Figura 1. Comprimento do bulbo da cenoura submetida a diferentes lâminas de irrigação e tipos de água. As médias seguidas de mesma letra, minúscula comparando o tipo de água e maiúscula comparando as lâminas de irrigação, não apresentam diferença estatística $(P \leq 0,05)$ de acordo com o teste Tukey. As barras de erro indicam o desvio padrão da média de 10 repetições $(n=10)$. ATM: água tratada magneticamente; AP: água potável.

A irrigação com AP provocou o menor incremento com a lâmina de reposição de $125 \%$ da ETc, devido ao efeito do excesso de água e o maior $\mathrm{CB}$ ocorreu quando irrigada com as lâminas de 50 e 75\% da ETc, assim acarretando no aumento de 50\%. Em função do tipo de água adotado na irrigação, observou que as lâminas de 25, 100 e 125 \% da ETc obtiveram um aumento quando submetida a irrigação com ATM, apresentando o efeito positivo no comprimento de bulbo da cenoura.

Não verificou reduções no comprimento de bulbo devido a disponibilidade de água no solo. Lima Junior et al. (2012) constatou que quando a tensão de água no solo foi de $-15 \mathrm{kPa}$ ocorreu a máxima produção e ocorreu o efeito significativo das lâminas de irrigação. A irrigação com ATM apresentou efeito significativo no comprimento de raiz do tomate (Selim e El-Nady, 2011). Também foi constatado por Putti et al. (2013) que ocorreu o aumento do comprimento do sistema radicular para a cultura da alface quando submetida a irrigação com ATM. Tal aumento possivelmente oriundo do comportamento da água quando submetida ao campo magnético, em que facilita a absorção e isso provoca o aumento na absorção de nutrientes e consequentemente o comprimento do bulbo (Putti et al., 2015).

O diâmetro de bulbo quando irrigado com diferentes lâminas de irrigação e tipos águas, apresentou efeito significativo, assim provocando um aumento devido a variação da taxa de aplicação (Fig. 2).

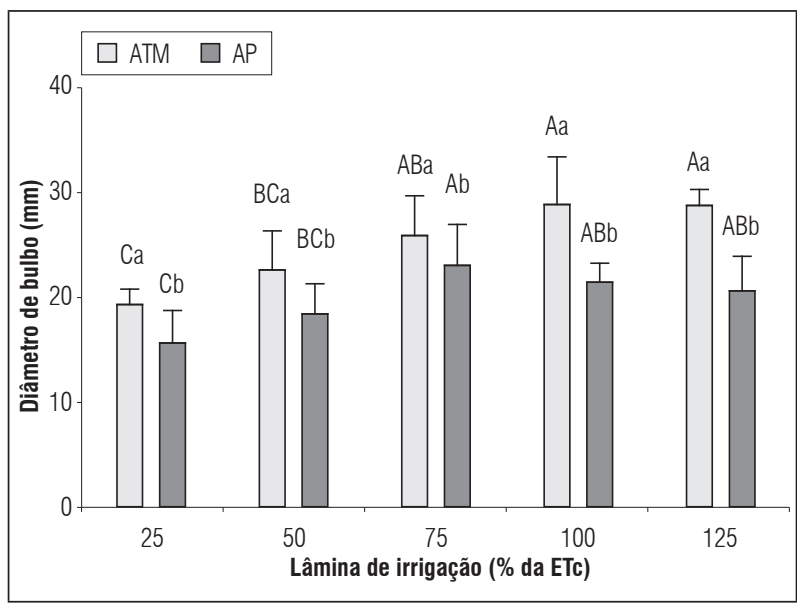

Figura 2. Diâmetro de bulbo da cenoura submetida a diferentes lâminas de irrigação e tipos de água. As médias seguidas de mesma letra, minúscula comparando o tipo de água e maiúscula comparando as lâminas de irrigação, não apresentam diferença estatística $(P \leq 0,05)$ de acordo com o teste Tukey. As barras de erro indicam o desvio padrão da média de 10 repetições $(n=10)$. ATM: água tratada magneticamente; AP: água potável. 
A irrigação com ATM, ocasionou um aumento até a lâmina de $100 \%$ da ETo $(P \leq 0,05)$. E para lâmina de $25 \%$ da ETo ocorreu o menor diâmetro de bulbo, sendo que a redução foi de $66 \%$.

Verificou-se que a irrigação com água tratada magneticamente proporcionou aumento significativo para todas as lâminas de irrigação.

Shibairo et al. (2000) e Souza et al. (2011) observaram que o déficit hídrico proporciona redução linear para o DB, em que devido ao estresse provocado, ocasiona turgescência na planta e leva a redução do processo fotossintético e assim reduzindo a produção de energia e açúcares e leva a redução da produtividade.

A massa fresca do bulbo apresentou efeito significativo quando irrigado com ATM e também quando comparada com AP (Fig. 3).

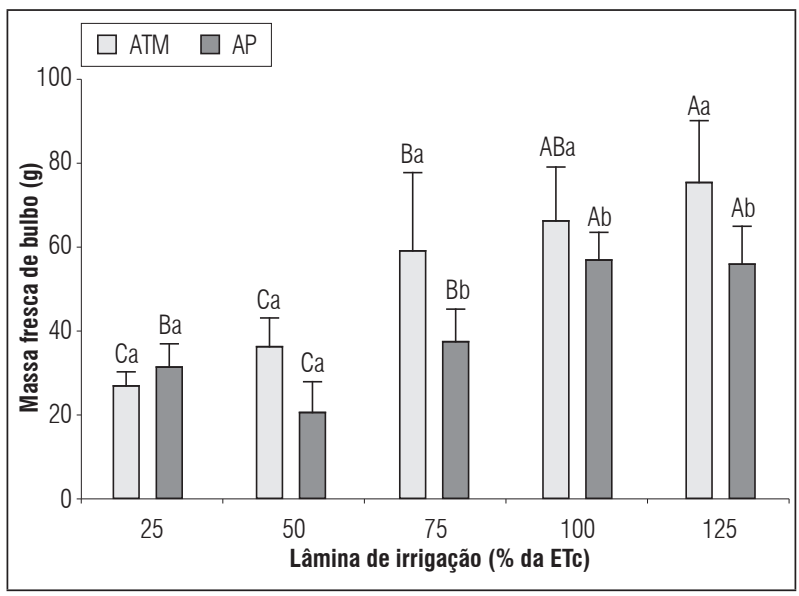

Figura 3. Massa fresca do bulbo da cenoura submetida a diferentes lâminas de irrigação e tipos de água. As médias seguidas de mesma letra, minúscula comparando o tipo de água e maiúscula comparando as lâminas de irrigação, não apresentam diferença estatística $(P \leq 0,05)$ de acordo com o teste Tukey. As barras de erro indicam o desvio padrão da média de 10 repetições $(n=10)$. ATM: água tratada magneticamente; AP: água potável.

Para a MFB, pode-se verificar que para as lâminas de 25 e $50 \%$ da ETC não houve diferença quanto a aplicação do tipo de água. Para as demais constatou-se que ocorreu maior peso, diferindo significativamente $(P \leq 0,05)$. Deve-se ressaltar que o potencial para a redução da aplicação de água magnética frente a sem o tratamento. Pois verificou-se que houve a FVB quando irrigada com $75 \%$ da ETc obteve resultado similar ao $100 \%$ da ETc com água sem o tratamento.

De acordo com estudo de Lima Junior et al. (2012), houve efeito linear negativo em função do aumento da disponibilidade hídrica, pois prejudicando seu desenvolvimento quando irrigado com a lâmina acima da recomendada. Também foi constatado por Putti et al. (2015) que a produtividade da alface apresentou um aumento significativo, sendo que a maior disponibilidade de água no solo, provavelmente favoreceu o aumento da absorção de nutrientes. Também constatado por Aladjadjiyan e Ylieva (2003) que a irrigação utilizando ATM favoreceu a produção de tabaco como também a qualidade.

Estudo envolvendo a ATM, constataram aumento na produção e, deve-se ressaltar que além das características de produção, também verificou o aumento nos teores de macro e micronutrientes nas cultivares, assim demonstrando-se um potencial de biofortificação de elementos necessários para a saúde humana (Aladjadjiyan e Ylieva, 2003; Maheshwari e Grewal, 2009; Selim et al., 2011; Rawabdeh et al., 2014; Sayed e Sayed, 2014; U1 Haq et al., 2016).

A massa seca do bulbo apresentou interação entre os fatores, conforme podemos verificar na figura 4 .

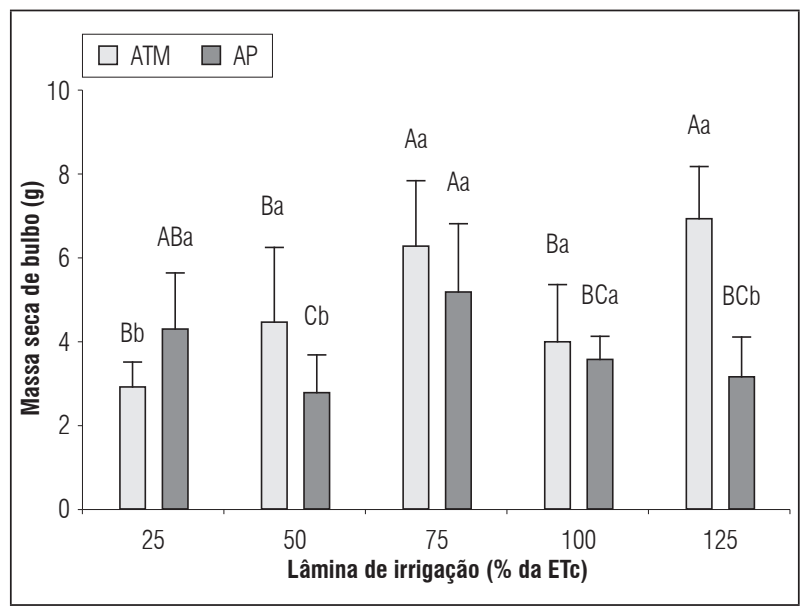

Figura 4. Massa seca do bulbo da cenoura submetida a diferentes lâminas de irrigação e tipos de água. As médias seguidas de mesma letra, minúscula comparando o tipo de água e maiúscula comparando as lâminas de irrigação, não apresentam diferença estatística $(P \leq 0,05)$ de acordo com o teste Tukey. As barras de erro indicam o desvio padrão da média de 10 repetições $(n=10)$. ATM: água tratada magneticamente; AP: água potável. 
Pode-se obervar que o efeito do tratamento magnético da água, apresentou para as lâminas de 50 e 125\% da ETc maior incremento de MSB, diferindo significativamente. Também constata-se que ocorreu o efeito das lâminas de irrigação em que o déficit hídrico e o excesso de água provocaram efeitos de redução de MSB.

O campo magnético quando em contato com a água provoca alterações em suas características físicas e químicas, como constatado por Lin e Yotvat (1990). Assim essas alterações levam diretamente a alterações no soluto do solo, sendo que o $\mathrm{pH}$ e Condutividade elétrica, fatores limitantes no desenvolvimento de plantas, sofrem redução (Grewal e Maheshwari, 2011; Khoshravesh et al., 2011).

O número de folhas da cenoura apresentou interação quando submetida a diferentes taxas de reposição da lâmina de irrigação e dos tipos de água (Fig. 5).

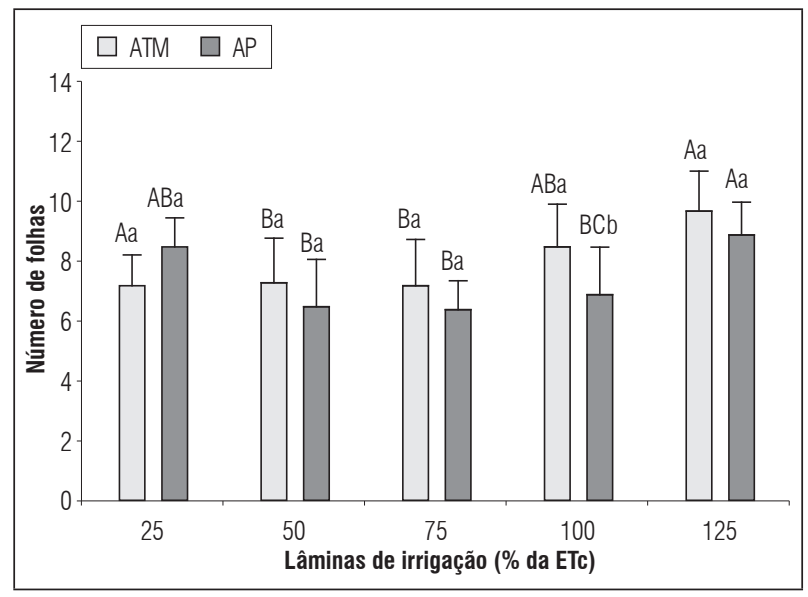

Figura 5. Número de folhas da cenoura submetida a diferentes lâminas de irrigação e tipos de água. As médias seguidas de mesma letra, minúscula comparando o tipo de água e maiúscula comparando as lâminas de irrigação, não apresentam diferença estatística $(P \leq 0,05)$ de acordo com o teste Tukey. As barras de erro indicam o desvio padrão da média de 10 repetições $(n=10)$. ATM: água tratada magneticamente; AP: água potável.

Nota-se, que a irrigação com água tratada magneticamente apresentou um maior incremento para as lâminas de $100 \%$ e $125 \%$ da ETc, assim se diferenciando estatisticamente $(P \leq 0,05)$.

Os tratamentos que foram irrigados com AP apresentaram maior número de folhas, para a lâmina de 125\% da ETc e os menos números com 50 e $75 \%$ da ETc. Ao comparar o efeito do tipo de água, observa-se que que apenas o tratamento $100 \%$ da ETc obteve maior acúmulo quando irrigado com ATM, assim acarretando em aumento de $23 \%$.

A massa fresca das folhas apresentou interação significativa $(P \leq 0,05)$ quando irrigadas com diferentes taxas de reposição e tipos de água (Fig. 6).

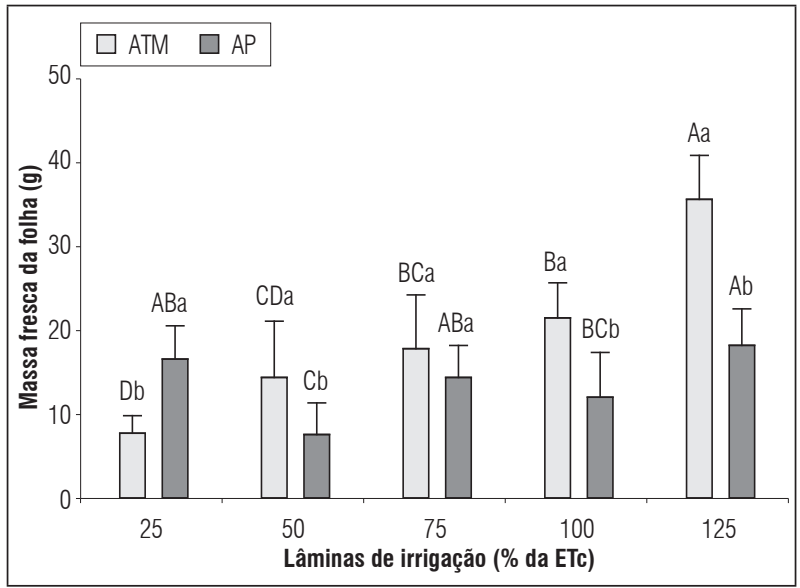

Figura 6. Massa fresca das folhas da cenoura submetida a diferentes lâminas de irrigação e tipos de água. As médias seguidas de mesma letra, minúscula comparando o tipo de água e maiúscula comparando as lâminas de irrigação, não apresentam diferença estatística $(P \leq 0,05)$ de acordo com o teste Tukey. As barras de erro indicam o desvio padrão da média de 10 repetições $(n=10)$. ATM: água tratada magneticamente; AP: água potável.

A MFF representa indiretamente a área foliar, e podese constatar que a relação direta com a MFB, pois isso pode ter provocado maior taxa fotossintética e assim acarretando em maior produção de cenoura. Nas lâminas de reposição utilizando AP, observa-se que ocorreu maior incremento para as lâminas de 125\% da ETc e o menor para a lâmina de $50 \%$ da ETc, este fato é oriundo devido a baixas lâminas de reposição e assim acarretando no estresse hídrico.

Para a irrigação utilizando ATM, verificou-se que ocorreu a sinergia positiva em função das lâminas de irrigação, pois a disponibilidade de água no solo fez com o que as folhas apresentassem maior desenvolvimento, assim podendo ocorrer os processos fisiológicos. Pode-se constatar que a lâmina de $125 \%$ da ETc apresentou maior MFF e a menor com 25\% da ETc, assim apresentando a redução de $78 \%$. 
Para massa seca das folhas constatou o efeito das lâminas de irrigação sob a influência do topo de água adotado (Fig. 7).

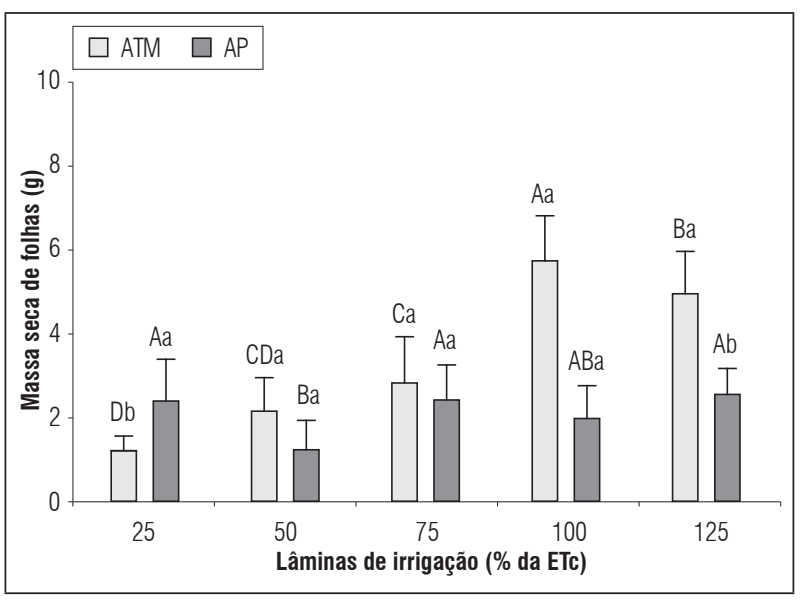

Figura 7. Massa seca das folhas da cenoura submetida a diferentes lâminas de irrigação e tipos de água. As médias seguidas de mesma letra, minúscula comparando o tipo de água e maiúscula comparando as lâminas de irrigação, não apresentam diferença estatística $(P \leq 0,05)$ de acordo com o teste Tukey. As barras de erro indicam o desvio padrão da média de 10 repetições $(n=10)$. ATM: água tratada magneticamente; AP: água potável.

A MSF apresentou efeito significativo quando submetido ao estresse hídrico, para ambos os tipos de água. Entretanto quando irrigado com ATM, pode-se constatar que ocorreu um incremento até a lâmina de $100 \%$ da ETc, e após a redução no acúmulo de MSF.
Tal fato é oriundo devido a desregulação dos processos fisiológicos essenciais para o desenvolvimento da planta, tanto pelo estresse hídrico como pelo excesso de água no solo (Taiz e Zeiger, 2013).

Para os tratamentos irrigados com 25 e $125 \%$ da ETc, verificou-se um maior número de folhas e acúmulo de MFF, esse mesmo resultando foi observado para o MSF.

Para os componentes MFF, MSF e NF foi constatado por Putti et al. (2015) que para a cultura da alface, ocorre maior incremento. Tal fato provavelmente é oriundo da maior disponibilidade hídrica no solo, que deste modo ocasiona maior absorção de nutrientes. Tais componentes tem relação direta com a taxa fotossintética, assim pode constar para os tratamentos irrigados com lâmina de 100 e 125\% apresentaram os maiores acúmulos e ocasionou-se as maiores MFB.

Observa-se, que para os tratamentos irrigados com água tratada magneticamente, ocorreu incremento de MSF até a lâmina de $100 \%$ da ETc e devido ao excesso de água no solo ocorreu redução no acúmulo de massa seca. Ao analisar o efeito do tipo de água nos tratamentos, verificaram que para as lâminas de 100 e $125 \%$ da ETc, ocorreram maior acúmulo quando irrigadas com ATM.

Diante dos resultados obtidos para a irrigação com ATM, buscou-se mitigar a eficiência do uso da água, que consideram a da relação de produção com a lâmina de irrigação aplicada. Neste sentido pode constatar que a irrigação utilizando água magnetizada apresentou maior eficiência no uso da água, tais resultados são apresentados na (Fig. 8).

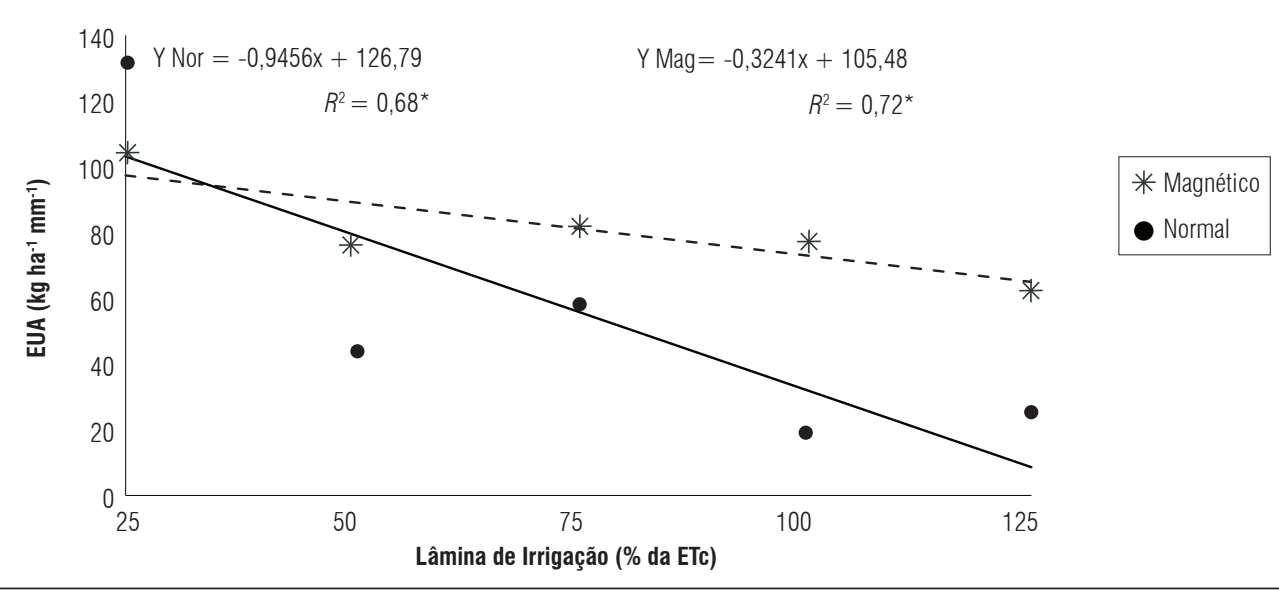

Figura 8. Eficiência do uso de água (EUA) na cultura da cenoura submetida a irrigação com diferentes lâminas de irrigação e tipos de água. 
Pode-se constatar que o aumento de 1\% da ETc faz reduzir em $0,95 \mathrm{~kg}$ quando irrigada com $\mathrm{AP}$, já quando adotada a irrigação com ATM a redução chega a apenas $0,32 \mathrm{~kg}$, deste modo apresentando a eficiência no uso da ATM. A cenoura por se tratar de uma Apiaceae que desenvolve sua parte comercial no solo, apresenta alta correlação com a disponibilidade de água e as condições de solo como $\mathrm{pH}$, condutividade elétrica e fertilidade. Assim, a ATM quando em contato com o solo altera suas propriedades químicas e físicas, sendo que ocorre a redução do $\mathrm{pH}$ e aumento da condutividade (Zhou et al., 2000). Silva et al. (2011) observaram que o acréscimo da taxa de reposição de água ocasionou um aumento na produtividade, sendo que o máximo foi encontrado com $136 \%$ da ETc. Khoshraves et al. (2011) verificaram que ocorreu o efeito da redução da força das moléculas de água, o que ocasiona redução do potencial matricial do solo, que leva a redução da tensão, favorecendo o potencial osmótico, que acarreta a redução no dispêndio de energia, levando ao maior desenvolvimento.

\section{CONCLUSÕES}

Pode-se concluir que o uso de ATM proporciona aumento no desenvolvimento da cultura da cenoura, em que ocasionou maior produção. E para lâmina de $100 \%$ da ETC com ATM proporcionou a maior produção, assim se tornando uma forma sustentável de otimizar o uso da água.

Conflito de interesses: o manuscrito foi preparado e revisado com a participação de todos os autores, que declaram não ter qualquer conflito de interesses que possa afetar a validade dos resultados do trabalho apresentado.

\section{REFERÊNCIAS BIBLIOGRÁFICAS}

Aladjadjiyan, A. e T. Ylieva. 2003. Influence of stationary magnetic field on the early stages of the development of tobacco seeds. J. Central Eur. Agric. 4(2), 1-8. Doi: 10.5513/jcea.v4i2.167

Allen, R.G., L.S. Pereira, D. Raes e M. Smith. 1998. Crop evapotranspiration-guidelines for computing crop water requirements. FAO Irrigation and Drainage Paper 56. FAO, Roma.

Banzatto, D.A. e S.N. Kronka. 2006. Agricultural experimentation. Fundação de Apoio a Pesquisa, Ensino e Extensão, Jaboticabal-SP, Brasil.
Carvalho, R., A.E. Furtine Neto, C. Nilton e L.A. Fernandes. 2000. Dessorção de fósforo por silício em solos ácidos. Rev. Bras. Ciênc. Solo 24, 69-74. Doi: 10.1590/ S0100-06832000000100009

Grewal, H.S. e B.L. Maheshwari. 2011. Magnetic treatment of irrigation water and snow pea and chickpea seeds enhances early growth and nutrient contents of seedlings. Bioelectromagnetics 32(1), 58-65. Doi: 10.1002/ bem. 20615

Lima Junior, J.A., G.M. Pereira, L.O. Geisenhoff, W.G. da Silva, R.C.V. Boas e R.J. Souza. 2012. Desempenho de cultivares de cenoura em função da água no solo. Rev. Bras. Eng. Agríc. Ambient. 16(5), 514-520. Doi: 10.1590/S1415-43662012000500007

Khoshravesh, M., B. Mostafazadeh-Fard, S.F. Mousavi e A.R. Kiani. 2011. Effects of magnetized water on the distribution pattern of soil water with respect to time in trickle irrigation. Soil Use Manage. 27, 515-522. Doi: 10.1111/j.1475-2743.2011.00358.x

Köppen, W. e R. Geiger 1928. Klimate der Erde. Verlag Justus Perthes, Gotha, Alemanha.

Lin, I.J. e J. Yotvat. 1990. Exposure of irrigation and drinking water to a magnetic field with controlled power and direction. J. Mag. Mag. Mat. 83(1), 525-526. Doi: 10.1016/0304-8853(90)90611-S

Maheshwari, B.L. e H.S. Grewal. 2009. Magnetic treatment of irrigation water: its effects on vegetable crop yield and water productivity. Agric. Water Manag. 96, 12291236. Doi: 10.1016/j.agwat.2009.03.016

Mohamed, A.I. 2013. Effects of magnetized low quality water on some soil properties and plant growth. Int. J. Res. Chem. Environ. 3(2), 140-147.

Marouelli, W.A., W.L. Silva e C.L. Moretti. 2002. Desenvolvimento de plantas, produção e qualidade de bulbos de alho sob condições de deficiência de água no solo. Hortic. Bras. 20(3), 470-473. Doi: 10.1590/ S0102-05362002000300014

Putti, F.F., L.R.A. Gabriel Filho, A.E. Klar, C.P. Cremasco, R. Ludwig e J.F. Silva Junior. 2013. Desenvolvimento inicial da alface (Lactuca sativa L.) irrigada com água magnetizada. Rev. Cultivando o Saber 6(3), 83-90.

Putti, F.F., L.R.A. Gabriel Filho, A.E. Klar, J.F. Silva Junior, C.P. Cremasco e R. Ludwig. 2015 Response of lettuce crop to magnetically treated irrigation water and different irrigation depths. Afr. J. Agr. Res. 10(22), 23002308. Doi: 10.5897/AJAR2015.9616

Rawabdeh, H., S. Shiyab e R. Shibl. 2014. The effect of irrigation by magnetically water on chlorophyll and macroelements uptake of pepper (Capsicum annuum L.). Jordan J. Biol. Sci. 10(2), 205-21.

Sayed, H. e A. El Sayed, 2014. Impact of magnetic water irrigation for improve the growth, chemical composition and yield production of broad bean (Vicia faba L.) plant. Am. J. Exp. Agric. 4(4), 476-496. Doi: 10.9734/ AJEA/2014/7468 
Selim, A.F.H. e M.F. El-Nady. 2011. Physio-anatomical responses of drought stressed tomato plants to magnetic field. Acta Astronaut. 69(7), 387-396. Doi: 10.1016/j. actaastro.2011.05.025

Shibairo, S.I., M.K. Upadhyaya e P.M.A. Toivonen. 2002. Changes in water potential, osmotic potential, and tissue electrolyte leakage during mass loss in carrots stored under different conditions. Sci. Hortic. 95, 1321. Doi: 10.1016/S0304-4238(02)00034-1

Silva, V.J., R.E.F. Teodoro, C.H. Paula, A.D. Martins e J.M.Q. Luz. 2011. Response of the application of carrot different irrigation. Biosci. J. 27(6), 954-963.

Snyder, R.L. 1992. Equation for evaporation pan to evapotranspiration conversions. J. Irrig. Drain. Eng. 118(6), 977-980. Doi: 10.1061/ (ASCE)0733-9437(1992)118:6(977)
Souza, E.R., A.A. de A. Montenegro, S.M.G. Montenegro e J.A. de Matos. 2011. Temporal stability of soil moisture in irrigated carrot crops in Northeast Brazil. Agric. Water Manag. 99, 26-32. Doi: 10.1016/j. agwat.2011.08.002

Taiz, L. e E. Zeiger. 2013. Elementi di fisiologia vegetale. Piccin-Nuova Libraria, Pádua, Itália.

U1 Haq, Z., M. Iqbal, Y. Jamil, H. Anwar, A. Younis, M. Arif, Z. Fareed e F. Hussain. 2016. Magnetically treated water irrigation effect on turnip seed germination, seedling growth and enzymatic activities. Inf. Proces. Agric. 3(2), 99-106. Doi: 10.1016/j.inpa.2016.03.004

Zhou, K.X., G.W. Lu, Q.C. Zhou, J.H. Song, S.T. Jiang e H.R. Xia. 2000. Monte Carlo simulation of liquid water in a magnetic field. J. Appl. Phys. 89, 1802-1805. Doi: 10.1063/1.1305324 